\title{
Adaptive responses in short-chain fatty acid absorption, gene expression, and bacterial community of the bovine rumen epithelium recovered from a continuous or transient high-grain feeding
}

\author{
R. M. Petri, ${ }^{1,2 *}$ S. U. Wetzels, ${ }^{1,2,3}$ M. Qumar, ${ }^{1}$ R. Khiaosa-ard, ${ }^{1,2}$ and Q. Zebeli ${ }^{1,2}$ \\ ${ }^{1}$ Institute of Animal Nutrition and Functional Plant Compounds, \\ ${ }^{2}$ Animal Gut Health Research Cluster, and \\ ${ }^{3}$ Institute for Milk Hygiene, Milk Technology and Food Science, University of Veterinary Medicine Vienna, Veterinaerplatz 1, 1210 Vienna, Austria
}

\begin{abstract}
The feeding of high-grain diets to dairy cows commonly results in lowered $\mathrm{pH}$ and ruminal dysbiosis, characterized by changes in absorption dynamics of short-chain fatty acids (SCFA) across the reticuloruminal wall, epithelial function, and the epithelial bacteria community structure. Therefore, the present study evaluated the effect of high-grain feeding persistence on the absorption kinetics of reticuloruminal SCFA, gene expression in the rumen epithelium, and the associated shifts in the epithelial bacteria in cows recovering from either a long-term continuous high-grain feeding model or a long-term transient high-grain feeding model. In a crossover study design, 8 nonlactating Holstein cows were fed $60 \%$ concentrate either continuously for 4 wk (continuous) or with a 1-wk break in the second week of the high-grain feeding (transient). After the high-grain feeding, all animals were fed a diet of $100 \%$ forage (recovery) for an additional 8 wk. Rumen papilla biopsies and SCFA absorption measurements were taken at the start of the trial (baseline), after the 4-wk high-grain feeding (49 d), after 2-wk recovery forage feeding $(63 \mathrm{~d})$, and after 8 -wk recovery forage (105 d). Absorption of SCFA was determined in vivo using the washed and isolated reticulorumen technique. Rumen papillae biopsies were used for adherent bacterial DNA and host RNA extraction. The epithelial bacteria were determined using Illumina MiSeq (Microsynth AG, Balgach, Switzerland) sequencing of the $16 \mathrm{~S}$ rRNA gene. No significant effects of the high-grain feeding model were seen for bacterial diversity. However, bacterial diversity increased with time spent in the recovery forage feeding period regardless of feeding model. The relative abundance of Acidobacteria phyla and Acetivibrio spp. increased when animals were fed a transient
\end{abstract}

Received September 14, 2018.

Accepted March 5, 2019.

*Corresponding author: renee.petri@vetmeduni.ac.at high-grain feeding model. A trend toward increased CLDN4 expression was observed in the continuous model. Furthermore, there were interactions between feeding model and sampling day for gene targets $C D 14$, DRA, NHE2, NHE3, and MCT2. When comparing length of recovery, in the continuous model increased relative absorption of SCFA was sustained at $63 \mathrm{~d}$ but dropped to baseline measurements at $105 \mathrm{~d}$. A similar pattern was found with the transient model but it did not reach significance. The only gene target that was found to significantly correlate to relative absorption of SCFA was DRA (correlation coefficient $\leq-0.41$ ). Whereas, genera Alkalibaculum, Anaerorhabdus, Coprococcus, and Dethiobacter all showed positive correlations to gene targets for $\mathrm{pH}$ regulation (NHE2 and NHE3) and SCFA uptake (MCT1) but negative correlations to SCFA absorption. We conclude that while the rumen absorption and epithelial bacteria were able to recover to baseline levels after $8 \mathrm{wk}$ of forage feeding, the time needed for re-establishment of homeostasis in host gene expression is longer, especially when high-grain feeding is interrupted.

Key words: gene expression, ruminal absorption, rumen epithelium, bacteria

\section{INTRODUCTION}

Modern dairy production uses rapidly fermentable nutrient-dense diets to support consistent improvements in milk yield (Plaizier et al., 2008). These diets replace forage with high proportions of grain resulting in a rapid accumulation of short-chain fatty acids (SCFA). The rapid accumulation of acids and resulting decrease in $\mathrm{pH}$ for extended periods $(4-6 \mathrm{~h}$; Nocek et al., 2002) result in a rumen dysbiosis referred to as SARA (Khafipour et al., 2009b). The effects of SARA extend beyond ruminal $\mathrm{pH}$ to include rumen microbial changes (Petri et al. 2013a,b), epithelial damage (Steele et al., 2011), inflammation (Khafipour et al., 2009b), decreased DMI (Kleen et al., 2003), and liver abscesses 
(Dirksen, 1985). However, the severity of SARA and the subsequent effects on animal health and production are based on feeding conditions. Previous research has often focused on a permanent exposure to SARA, mostly conducted over a short period of time lasting (1 d or 2 wk; Dirksen et al., 1984; Dohme et al., 2008; Khafipour et al., 2009a). However, in a dairy herd cows often experience SARA conditions that go far beyond 1 to 2 wk. Under farm conditions, SARA might also be transient as animals temporally alter their intake pattern to restore ruminal balances (Gao and Oba, 2016). Therefore, our group conducted a long-term SARA model to compare both continuous and transient feeding in nonlactating dairy cows. We previously showed that reticulorumen SCFA absorption is increased with prolonged high-grain feeding (Qumar et al., 2016), and that rumen $\mathrm{pH}$ changes in SARA were more severe in transient feed cows (Pourazad et al., 2016). These changes in rumen environment affected the attachment of rumen microbes to forages incubated in situ (Petri et al., 2017). Additionally, the rumen epithelial (epimural) bacteria were shown to be less stable due to transient feeding (Wetzels et al., 2016), and that long-term continuously challenged epithelial microbes are significantly reduced in diversity (Wetzels et al., 2017). There are indications that the rumen epithelium elicits an adaptive response to high-grain feeding at the gene expression level by increasing barrier function (McCann et al., 2016), changing the expression of SCFA transporters and rumen epithelial cell metabolism enzymes (Laarman et al., 2013; Zhao et al., 2019), as well as inflammation-related gene expression (Zhang et al., 2016). The sensitivity of the epithelial bacterial community to changes in the diet (Petri et al., 2013a) as well as an effect of the host on the rumen microbial community (Weimer et al., 2010) might be associated with the involvement in barrier function, localized immune response, as well as SCFA transport.

Whereas rumen adaptation to high-grain diets is time dependent (Dirksen, 1985), damage to the rumen epithelium may occur under low pH conditions (Penner et al., 2011) and would depend on the duration and severity of decreased pH (Steele et al., 2011). Therefore, it is plausible that high-grain feeding could have a long-lasting effect on the reticulorumen. However, there is a lack of information on the effect of the SARA feeding model on the recovery of the rumen ecosystem with specific attention to the interface where rumen bacteria and SCFA are in direct contact with the host. Understanding such recovery processes is especially important for dairy cows undergoing repeated cycles of dietary change and may explain why the severity of SARA could change after repeated high-grain feeding periods (Dohme et al., 2008). Therefore, the aim of this study was to assess the effect of high-grain feeding (continuous vs. transient) on the recovery (return to baseline) of rumen SCFA absorption capacity (washed reticulorumen technique, gene expression for SCFA transport, $\mathrm{pH}$ regulation, rumen barrier function, epithelial inflammation, and the epimural bacteria community in the rumen). We hypothesized that cattle fed a transient high-grain diet would show differences from cattle fed a continuous high-grain diet in gene expression related to SCFA absorption, barrier function, and inflammation, which would correspond to changes in the reticulorumen absorption rates and rumen epimural bacterial community composition in the short-term recovery but that these feeding-model-related changes would not be seen after an 8-wk recovery period in which only forage was fed.

\section{MATERIALS AND METHODS}

\section{Animals and Experimental Design}

The effects of different feeding models during a highgrain challenge have been previously described in the associate publications (Pourazad et al., 2016; Qumar et al., 2016; Wetzels et al., 2016, 2017). In this paper we only focus on the data of the end of high-grain feeding and recovery from high-grain feeding in different feeding models. The samples taken at the baseline sampling time point were the only samples re-analyzed from previous data for use in the current study. Using 2 different previously described high-grain feeding models, transient (Wetzels et al., 2016) and continuous (Wetzels et al., 2017), 8 rumen-cannulated (100-mm inner diameter; Bar Diamond, Parma, ID), nonlactating Holstein cows (initial BW: $710 \pm 118 \mathrm{~kg}$, mean $\pm \mathrm{SD}$ ) were randomly allocated in a longitudinal crossover design feeding study. The experiment was conducted in 2 separate runs, each 15 wk in length, with 4 cows per model per run. Animals were kept together in a loose housing barn at the research farm of the University of Veterinary Medicine Vienna (Pottenstein, Austria). The animal experimental protocol of this research was reviewed and approved by the institutional ethics committee of the University of Veterinary Medicine Vienna, and all procedures were carried out in accordance with Good Scientific Practice guidelines and the national authority according to section 26 of Law for Animal Experiments (2012; GZ 68.205/0093-II/3b/2013).

\section{Feed and Feeding Models}

Ingredient and chemical composition of the experimental diets as well as the dietary adaptation has been previously reported by Pourazad et al. (2016). In brief, 
the continuous high-grain feeding model was as follows: 2 wk of $100 \%$ forage feeding, followed by 1 wk of gradual adaptation to a $60 \%$ concentrate diet, followed by 4 wk of continuous feeding with $60 \%$ concentrate (Figure 1). The transient high-grain feeding model was similar to the continuous with the exception that, after the 1-wk adaptation to a $60 \%$ concentrate diet, the high-grain diet was given for 1 wk followed by 1 wk of $100 \%$ forage feeding and then a second 2 -wk high-grain feeding period with a brief 2-d stepwise adaptation to $60 \%$ grain feeding (Figure 1). Cows that did not completely consume their concentrate allowance during the high-grain feeding had the orts supplied via the cannula. At the end of the high-grain feeding for both models, animals were returned to a $100 \%$ forage diet for an 8-wk period (recovery). Access to fresh feed and water was continuously provided. During the grain feeding periods, cows had daily access to forage at 0800 $\mathrm{h}$ and concentrate at $1000 \mathrm{~h}$.

\section{Reticulorumen SCFA Absorption and Calculations}

The SCFA absorption across the reticuloruminal epithelium of all cows was determined by the temporarily isolated and washed reticuloruminal procedure (Qumar et al., 2016). Briefly, the washed reticuloruminal procedure was conducted 4 times in each feeding model: $14 \mathrm{~d}$ as a baseline, at the end of the high-grain feeding at $49 \mathrm{~d}$, and at $63 \mathrm{~d}$ and $105 \mathrm{~d}$ during the forage feeding recovery phase (Figure 1). For each analysis, the reticulorumen content was manually evacuated and then the reticulorumen was isolated from the rest of the gastrointestinal tract by occluding the esophagus with a nasogastric tube for saliva collection (University of Leipzig, Leipzig, Germany), and the omasal orifice with a Foley balloon catheter (Rusch Gold Foley Catheter 30-50 mL, Teleflex Medical, Athlone, Ireland; Qumar et al., 2016). After a washing procedure, $20 \mathrm{~L}$ of experimental buffer solution $\left[\mathrm{CaCl}_{2}(2 \mathrm{mM}), \mathrm{MgCl}_{2}(2 \mathrm{mM})\right.$,

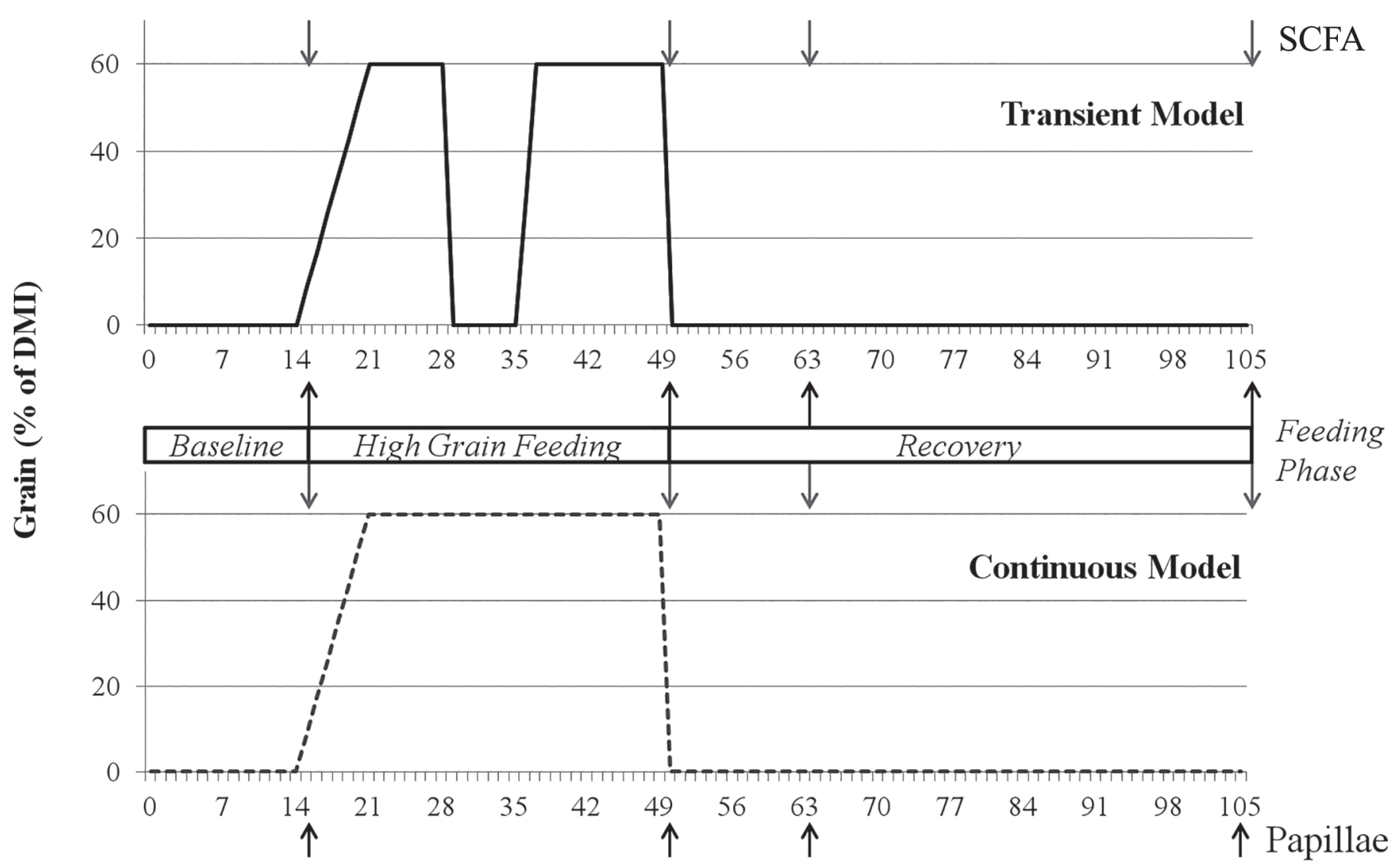

\section{Days of Experiment}

Figure 1. Visualization of the continuous and transient high-grain feeding models with feeding phases and sampling times. Arrows pointed downward represent the sampling for short-chain fatty acid (SCFA) absorption, and the arrows pointed upward represent the sampling times for papillae biopsies. 
$\mathrm{NaCl}(10 \mathrm{~m} M)$, sodium acetate $(60 \mathrm{~m} M), \mathrm{K}_{2} \mathrm{HPO}_{4}(5$ $\mathrm{m} M)$, sodium propionate $(30 \mathrm{~m} M)$, butyrate $(10 \mathrm{mM})$, and $\mathrm{NaHCO}_{3}(25 \mathrm{mM})$ ] was infused into the reticulorumen and the rumen cannula was sealed with a foam lid. The buffer was continuously gassed with $\mathrm{CO}_{2}$ during the procedure. The buffer samples were collected at 0 (before infusion), 35, and $65 \mathrm{~min}$ and stored at $-20^{\circ} \mathrm{C}$ for further SCFA analyses. After the procedure saliva was poured back into the reticulorumen, ruminal digesta was restored, and the cannula was closed.

The concentration of the test SCFA (acetate, propionate, and butyrate) was determined by GC and quantified by known quantities of standards (internal standard, 4-methylvaleric acid, and external standard, acetate:propionate:butyrate at 3:2:1 vol/vol/vol; Sigma-Aldrich Co. LLC, St. Louis, MO), following the protocol previously described in detail by Qumar et al. (2016). The absolute absorption rates $(\mathrm{mmol} / \mathrm{h})$ at 0 to $35 \mathrm{~min}$ and 35 to $65 \mathrm{~min}$ were estimated as follows:

$$
\text { rate }(\mathrm{mmol} / \mathrm{h})=\frac{(\mathrm{S} 1-\mathrm{S} 2)}{(\mathrm{T} 2-\mathrm{T} 1)} \times 60
$$

where S1 and S2 are the initial and final amounts of analyte in $20 \mathrm{~L}$ of experimental buffer solution respectively, $\mathrm{T} 1$ is the initial time point, and $\mathrm{T} 2$ is the final time point (min). Subsequently, changes in the SCFA absorption rate for each sampling $(49,63$, and $105 \mathrm{~d})$ were calculated in relation to the baseline value for each cow before subjecting to statistical analysis as follows:

$$
\text { relative change }(\% \text { of baseline })=\frac{(\text { phase }- \text { base })}{\text { base }} \times 100 \text {. }
$$

\section{Rumen Papillae Sampling}

Before performing the washed reticuloruminal procedure, rumen papillae biopsies (whole papillae of $\sim 1$ $\mathrm{cm}^{3}, 0.5 \mathrm{~g}$ in triplicate) were excised from the ventral rumen wall with aseptic scissors and tweezers after a partial evacuation of the rumen. Rumen papillae biopsies were taken from the rumen wall of the ventral sac about 40 to $50 \mathrm{~cm}$ below the bottom edge of the rumen cannula located in the left fossa paralumbalis, using the method described previously by Wetzels et al. (2016). Papillae were rinsed with sterile $1 \times$ PBS, cut in small pieces, snap frozen in liquid nitrogen, and stored at $-80^{\circ} \mathrm{C}$ for further analysis. Sampling occurred at $14 \mathrm{~d}$ as a forage baseline, after $4 \mathrm{wk}$ of high-grain feeding (49 d) and then at $63 \mathrm{~d}$ as short (recovery 1) and $105 \mathrm{~d}$ as long-term recovery (recovery 2 ) samples in both models (Figure 1).

\section{DNA Extraction, Sequencing, and Analysis}

Rumen papillae biopsies were thawed on ice and genomic DNA was extracted from $0.25 \mathrm{~g}$ of rumen papillae using the PowerSoil DNA Isolation Kit (Mo Bio Laboratories Inc., Carlsbad, CA) as described by Wetzels et al., (2016). Amplicon sequencing was performed using the Illumina MiSeq sequencing platform (Microsynth AG, Balgach, Switzerland). The V3-V5 hypervariable region of bacterial $16 \mathrm{~S}$ rRNA genes was amplified using the primer set 341F (5'-CCTACGGGRSGCAGCAG-3'; Zakrzewski et al., 2012) and 909R (5'-TTTCAGYCTTGCGRCCGTAC-3'; Tamaki et al., 2011) to generate paired-end reads of $300 \mathrm{bp}$. The $16 \mathrm{~S}$ rRNA gene PCR, library preparation, and sequencing were performed by Microsynth as described by Wetzels et al. (2016). Briefly, libraries were constructed by ligating sequencing adapters and indices onto purified PCR products. The Nextera XT Sample Preparation Kit (Illumina) was used according to the manufacturer's recommendations. After sequencing, corresponding overlapping paired-end reads were stitched to get an approximate amplicon size of $568 \mathrm{bp}$. Sequence data were analyzed with the software package Mothur (http://www.mothur .org/), according to the Illumina MiSeq procedure described by Kozich et al. (2013). Barcode sequences, primer, and low-quality sequences were trimmed using a minimum average quality score of 35 with a window size of $50 \mathrm{bp}$. Sequences were subsampled to 40,000 sequences per sample, and a total 2,093,194 sequences $(96.6 \%)$ passed the chimera check and quality control. These sequences were clustered into operational taxonomic units (OTU) with a $97 \%$ similarity cutoff (= 0.03 distance). The Silva SSU reference database v119 was used for alignment and the RDP trainset (trainset9_032012.rdp.tax) were used for taxonomic classification. All OTU with less than 10 sequences were removed (272,462 sequences). A total of 8,031 OTU (1,820,732 sequences) were used for downstream analysis. The nonparametric diversity estimates of coverage, Chao 1, the observed number of OTU, and Shannon diversity indices, were calculated using Mothur. Sequencing data are available in the National Center for Biotechnology Information short-read archive database under the accession number SRP158246.

\section{RNA Extraction, Reverse Transcription-PCR, and Host Gene Expression}

Rumen epithelium samples, stored on ice, were weighed and approximately $20 \mathrm{mg}$ was combined with lysis buffer (RNeasy Mini QIAcube kit, Qiagen, Hilden, Germany), according to the manufacturer's protocols, 
and autoclaved ceramic beads $(0.6 \mathrm{~g} ; 1.4 \mathrm{~mm}$; VWR, Radnor, PA). Samples were homogenized at a $6.5 \mathrm{~ms}^{-1}$ for $30 \mathrm{~s}$ using the FastPrep-24 (MP Biomedicals, Santa Ana, CA). The remainder of the RNA extraction protocol was completed using the automated QIAcube robotic workstation (Qiagen). After extraction, all samples were treated with Turbo DNA kit (Ambion, Foster City, CA) to remove genomic DNA and then quantification of RNA was determined with the Qubit 2.0 Fluorometer (Life Technologies, Carlsbad, CA) applying the Qubit RNA Assay kit (Life Technologies). The quality of extracted RNA was evaluated using the Agilent Bioanalyzer 2100 (Agilent RNA 6000 Nano Assay, Agilent Technologies, Santa Clara, CA) with an average RNA integrity number $(\mathbf{R I N})=7.2$. The majority of samples had a RIN value between 7 and 9; however, 5 samples had a RIN value range between 4.4 and 6.7. Complementary DNA was synthesized using $2 \mu \mathrm{g}$ of RNA diluted in $20 \mu \mathrm{L}$ of water combined with $20 \mu \mathrm{L}$ of master mix (High Capacity cDNA RT kit, Applied Biosystems, Waltham, MA) composed of $4 \mu \mathrm{L}$ of $10 \times$ reaction buffer, $1.6 \mu \mathrm{L}$ of $100 \mathrm{mM}$ of $25 \times$ deoxynucleotide triphosphate mix, $4 \mu \mathrm{L}$ of $10 \times$ random primers, $2 \mu \mathrm{L}$ of reverse transcriptase, and 7.4 $\mu \mathrm{L}$ of DNase/RNase-free water (diethylpyrocarbonate treated, G-Biosciences, St. Louis, MO), and $1 \mu \mathrm{L}$ of RNase inhibitor (Biozym, Hessisch Oldendorf, Germany) was added. The 2-step PCR was performed by a Mastercycler nexus (Eppendorf, Hamburg, Germany) using the following temperature program: incubation at $25^{\circ} \mathrm{C}$ for $10 \mathrm{~min}$, reverse transcription at $37^{\circ} \mathrm{C}$ for $120 \mathrm{~min}$, and a final heating step at $85^{\circ} \mathrm{C}$ for $5 \mathrm{~min}$. Reverse-transcription controls were completed as a control for residual DNA contamination.

Twenty-five gene targets were analyzed for the physiological parameters of tight junction complex, membrane transport, cellular $\mathrm{pH}$ regulation, cellular metabolism, and pattern recognition receptors. Primers used for rumen epithelium quantitative reverse-transcription PCR are listed in Supplemental Table S1 (https://doi .org/10.3168/jds.2018-15691). Target genes for barrier function (desmoglein1, DSG1; corneodesmosin, CSDN; zona occludens, TJP1; occludin, OCLN; claudin 1, 2, 4 , and $7, C L D N$ ), cell transport (monocarboxylate cotransporter, isoform 1,2, and $4, M C T$; downregulated in adenoma, DRA; anion exchange transporter, SLC26A6; proton/amino acid transporter 1, SLC36A1), cell metabolism (3-hydroxy-3-methyglutarylcoenzyme A synthase, isoform 1 and 2, HMGCS; $\beta$-hydroxybutyrate dehydrogenase, isoform 1 and $2, B D H)$, cellular $\mathrm{pH}$ regulation (anion exchanger isoform 2, AE2; sodium/ proton exchanger isoform 1, 2 and 3, NHE; sodium/ potassium ATPase transporting subunit alpha 1,
ATP1A1), pattern recognition receptors (toll-like receptor 4, TLR4; cluster of differentiation 14, CD14), and housekeeping genes (glyceraldehyde-3-phosphate dehydrogenase, GAPDH; $\beta$ actin, ACTB; hypoxanthine phosphoribosyltransferase 1, HPRT1; ornithine decarboxylase antizyme 1, OAZ1; tyrosine 3-monooxygenase/ tryptophan 5-monooxygenase activation protein, zeta, $Y W H A Z)$ were analyzed. The primers were designed and verified with PrimerBLAST using the Bos taurus genome (https://www.ncbi.nlm.nih.gov/tools/primer -blast/) and tested for efficiencies and specificity using melting curves (Supplemental Table S1, https:// doi.org/10.3168/jds.2018-15691; Ye et al., 2012). Each $20-\mu \mathrm{L}$ reaction consisted of $50 \mathrm{ng}$ in $1 \mu \mathrm{L}$ of sample cDNA, $10 \mu \mathrm{L}$ of $1 \times$ Fast Plus Eva Green master mix with low ROX (Biotium, Hayward, CA), $1 \mu \mathrm{L}$ each of $200 \mathrm{n} M$ forward and reverse primers, and $7 \mu \mathrm{L}$ of DNase/RNase-free water in a 96-well plate (Agilent Technologies). Analysis was performed according to Petri et al. (2018). Briefly, all reactions were performed on a real-time PCR MX3000P (Agilent Technologies) thermocycler using the following conditions: $95^{\circ} \mathrm{C}$ for 5 min, followed by $60^{\circ} \mathrm{C}$ for $30 \mathrm{~s}$ and $72^{\circ} \mathrm{C}$ for $30 \mathrm{~s}$ for 40 cycles. The presence of a single PCR product was verified with an additional dissociation stage. Analysis of 5 reference genes was performed and the 3 best-fitting reference genes $(O A Z 1, H P R T 1$, and $Y W H A Z)$ were selected using NormFinder (Andersen et al., 2004) and BestKeeper (Pfaffl, 2001). The mRNA abundance of target genes was calculated using the cycle threshold (Cq) method, as previously described (Gui and Shen, 2016; Petri et al., 2018). The relative expression values were calculated by using the formula: relative expression $=2^{-\Delta \Delta \mathrm{Cq}}$ (Pfaffl, 2001). Relative expression was then calculated as a fold change relative to the baseline sample for each animal and each run to account for variation between the baselines in the crossover design and provide normalized data.

\section{Statistical Analysis}

All data were checked for the normality by means of the Shapiro-Wilk test to ensure that the data fit a normal distribution before hypothesis testing. Diversity indices, relative abundances, and epithelial gene expression data calculated as fold change were analyzed using the MIXED procedure of SAS 9.4 (SAS Institute Inc., Cary, NC). Terms in the model included the sequence of crossover, feeding model, and sample day with cow as random within run. However, due to significantly differing baselines between the feeding models all microbial and gene expression data were normalized to the baseline value for the corresponding experimental 
Table 1. Changes in relative ruminal absorption rate (\% increase or decrease in relation to baseline) of cows following high-grain feeding, and after 2 wk (recovery 1 ) and 8 wk (recovery 2 ) of forage-only feeding

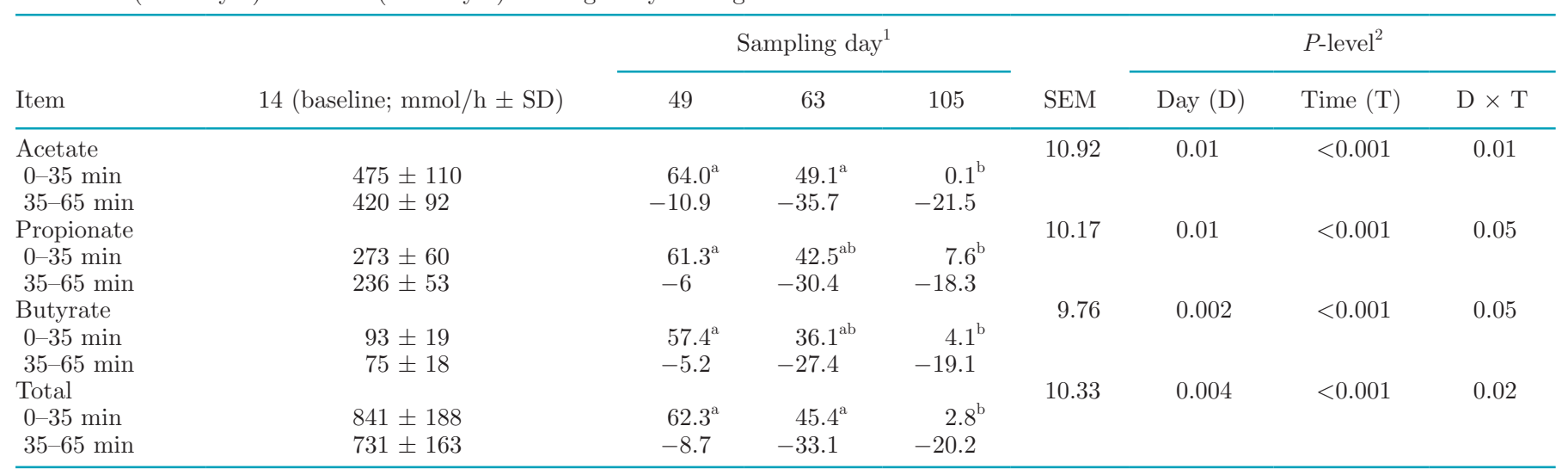

${ }^{\mathrm{a}, \mathrm{b}}$ Means with different superscripts differ at $P<0.05$ according to Tukey's method.

${ }^{1}$ Sampling day based on sample protocol in Figure 1. Data in baseline are expressed as absolute absorption determined at the beginning of the experiment when the cows were based on a forage-only diet.

${ }^{2}$ Mean values of both continuous and transient feeding models are presented because no significant effects of feeding model, model $\times$ incubation time, or model $\times$ phase were found. However, a tendency $(P<0.10)$ was observed for model $\times$ phase $\times$ incubation time in the case of acetate, butyrate, and total short-chain fatty acids (see Figure 2).

period before statistical analysis. Animal was considered the experimental unit and sampling day was a repeated measure with a first-order autoregressive covariance structure. Absorption data were analyzed with fixed effects of run, sequence of crossover, feeding model, sample day, incubation time (0-35 and 35-65 min of incubation), and 2-way and 3-way interactions. Animal was considered the experimental unit. Group means were calculated using the LSMEANS option, and data are expressed with standard error of the mean. Degrees of freedom were estimated using the Satterthwaite method. Means were separated using PDIFF. Significance was declared at a $P$-value of $\leq 0.05$, and trends were indicated at $0.05<P \leq 0.10$. Boxplots were created with the corrplot and ggplot2 packages (Wickham, 2009) in R Studio (version 1.0.136). To illustrate microbial and gene expression changes, linear canonical discriminant analysis was done in JMP Pro (version 14, 2018; SAS Institute Inc.) with genera or gene expression as covariates and sampling period as the categorical variable. Correlation of various parameters was performed using the CORR procedure of SAS. According to Hinkle et al. (2003) the correlation coefficient was interpreted as follows: 0.00 to 0.30 as negligible, 0.30 to 0.50 as low, 0.50 to 0.70 as moderate, 0.70 to 0.90 as high, and 0.90 to 1.00 as substantial.

\section{RESULTS}

\section{SCFA Absorption}

Table 1 shows the absorption rates of SCFA at base and the absorption changes in relation to base with respect to sampling day and incubation time as mean values of the 2 feeding models. There was an effect of sampling day, incubation time, and day $\times$ time interaction on all SCFA tested $(P \leq 0.05)$. As expected, the absorption rates of SCFA increased during high-grain feeding. The relative change in absorption (\% of baseline) at 0 to $35 \mathrm{~min}$ of incubation ranged from 57.4 to $64 \%$ for the individual SCFA and was $62.3 \%$ for the total SCFA. The changes were sustained at $63 \mathrm{~d}$ in the first part of the recovery from high-grain feeding at $49 \mathrm{~d}$. Specifically, the relative changes in absorption of acetate and total SCFA on d 63 were similar to that of $49 \mathrm{~d}$, whereas the relative changes of propionate and butyrate were intermediate of 49 and $105 \mathrm{~d}$. The relative change at $105 \mathrm{~d}$ was a decrease to 0.1 to $7.6 \%$ of the baseline for the individual SCFA and to $2.8 \%$ for total SCFA, being significantly lower than high-grain feeding $(P<0.05)$.

A tendency was observed for a feeding model $\times$ sampling day $\times$ time interaction for acetate, butyrate, and total SCFA $(P<0.10)$. The relative changes in absorption with respect to the challenge model are depicted in Figure 2. The data show that the differences among feeding phases were most obvious in the continuous feeding model and at 0 to 35 min of incubation only. Specifically, high-grain feeding increased the absorption of all SCFA, and the levels, especially of acetate, were sustained up to 2 wk $(63 \mathrm{~d})$ after high-grain feeding ended. The absorption dropped to baseline levels at 8 wk of recovery forage feeding. Less dramatic changes were found for the transient feeding model at the 0 to 35 min incubation time. The relative absorption at 35 to $65 \mathrm{~min}$ of incubation showed decreased absorption 


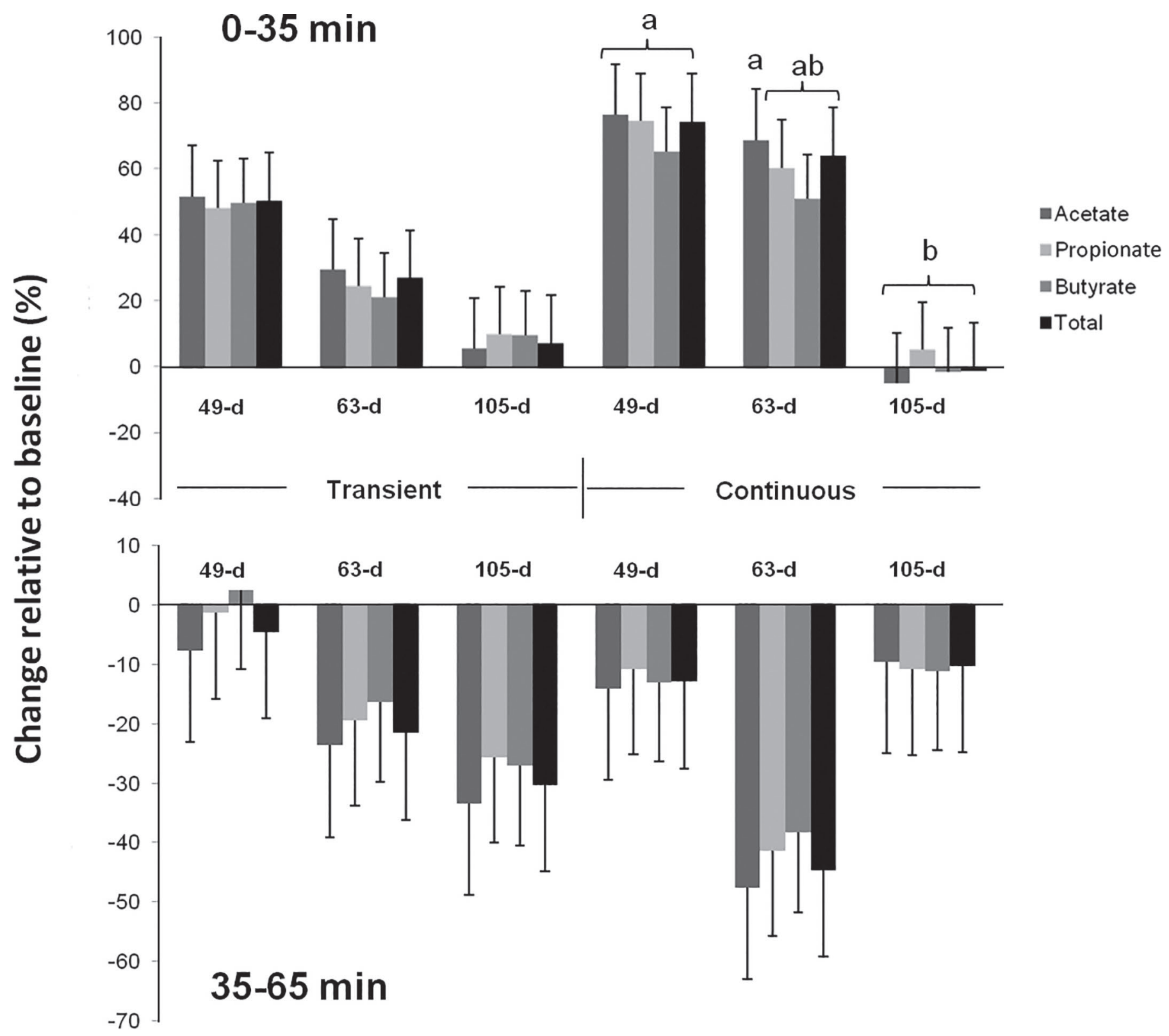

Figure 2. Short-chain fatty acid (SCFA) absorption relative to the baseline at 0 to 35 min and 35 to 65 min for both the transient and continuous high-grain feeding models. Error bars represent the SE of absorption within an SCFA, within a time point. Means within the challenge model sharing no common letters $(\mathrm{a}, \mathrm{b})$ differ $(P<0.05)$ according to Tukey's method.

(minus values), especially during the recovery forage feeding sampling days (Table 1 and Figure 2). Despite this variation, no differences were observed among feeding phases at this incubation time.

\section{Epimural Bacteria Diversity and Community Composition}

Diversity indices for nonparametric analysis showed an effect of sampling day for coverage $(P<0.001)$, ob- served species $(P<0.001)$, Shannon index $(P=0.02)$, and Chao 1 ( $P=0.004$; Figures $3 \mathrm{~A}-3 \mathrm{D}$, respectively). No effect of crossover or interaction between sampling and sequence was seen.

In total, 19 phyla were found. An average of $94.7 \%$ of the sequences identified were affiliated with Proteobacteria (44.1\% relative abundance), Firmicutes (35.0\% relative abundance), and Bacteroidetes (15.6\% relative abundance; Figure 4A). Synergistetes reached a relative abundance of $1.6 \%$, Elusimicrobia a relative 
abundance of $1.3 \%$, and the remaining phyla showed less than $1 \%$ relative abundance. Despite the relatively low abundance within the epithelial bacteria, 8 of the 14 phyla showed a significant effect of sampling day (Figure 4B). A significant effect of the feeding model was only found for Acidobacteria $(P=0.02)$, which was increased in relative abundance in the transient feeding model (Figure 4). A total of 288 genera were detected with Campylobacter, Kingella, and Brachymonas being the most abundant (17.6, 9.0, and $5.1 \%$ relative abundance, respectively). However, only Brachymonas showed a tendency toward being lower during highgrain feeding $(P=0.08)$. A list of the 100 most abundant genera is shown in Supplemental Table S2 (https: //doi.org/10.3168/jds.2018-15691), and of these only Acetivibrio spp. showed a significant effect of model $(P$ $=0.03$ ) with a relative abundance of $0.3 \%$ more in the transient feeding model. Of the 288 genera analyzed, 70 showed an effect of sampling day, and of those 70 only 17 belonged to a phyla that was also significantly affected by sampling day when compared between the feeding models (Figure 5). Genus Anerophaga from the phylum Bacteroidetes (2.67\% relative abundance) and
Bifidobacterium (0.8\% relative abundance) from the Actinobacteria phylum decreased in relative abundance with time in the recovery forage feeding. In contrast, Gordonibacter $(0.16 \%$ relative abundance; phyla Actinobacteria), Anaerorhabdus (0.68\% relative abundance; phyla Bacteroidetes), and Ornithobacterium (1.13\% relative abundance; phyla Bacteroidetes) all increased in relative abundance with increased time on forage feeding.

Linear canonical discriminant analysis of the significantly affected genera is shown in Figure 6, with the first 2 eigenvectors representing $96 \%$ of the variation between samples. Sampling days for both models tended to cluster together with a clear differentiation between the high-grain feeding and the recovery forage feeding samplings. The largest variability was seen in the ratios between Gordonibacter spp. and Coprococcus spp. with all other genera. These 2 genera also showed the longest link and therefore had the strongest reciprocal ratio relationship. Alkalibaculum spp. and Ornithobacterium spp. had a similar reciprocal relationship that matched to the separation between high-grain feeding and the second recovery forage sampling at $105 \mathrm{~d}$.
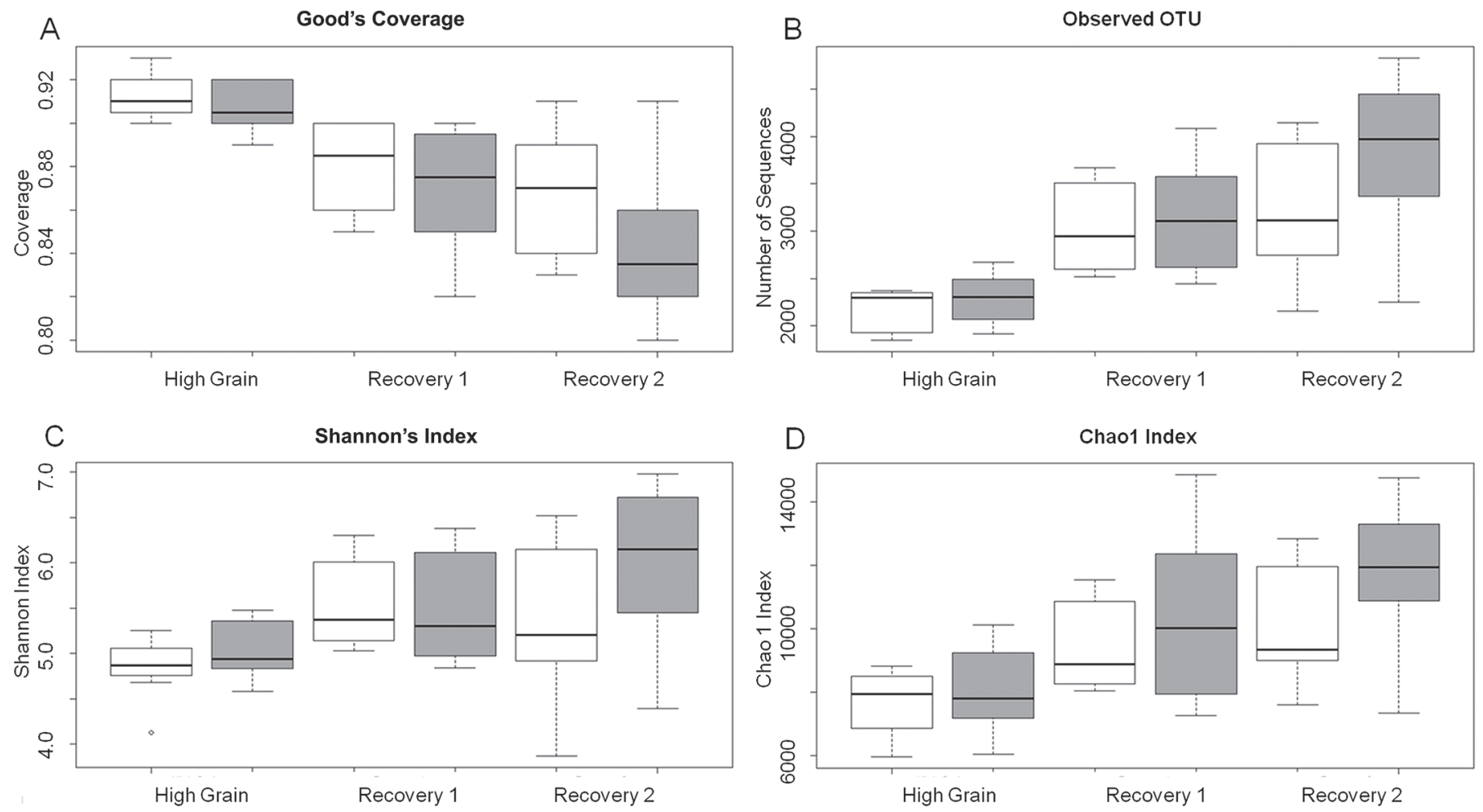

Figure 3. Whisker boxplots of nonparametric (alpha) diversity metrics coverage (A), observed number of species (B), Shannon index (C), and Chao 1 index (D) for samples in the continuous (white) feeding model or the transient (gray) feeding model during the high-grain feeding period, and in both the short $(63 \mathrm{~d})$ and long $(105 \mathrm{~d})$ recovery forage feeding. Boxplots represent the middle $50 \%$ of sample variation, with the median value indicated with a dark line and total variation indicated by whiskers. OTU = operational taxonomic units. 


\section{Relative Gene Expression}

There was no significant effect of the sequence of feeding model application. Gene targets $C D 14, D R A$, NHE2, NHE3, and MCT2 showed variation between the sampling days with relation to the feeding model (Figure 7). The CLDN4 was the only tight junction protein that tended to be higher in the continuous model 49 and $63 \mathrm{~d}(P=0.10)$. The MCT2 showed a decrease throughout both feeding models in relation to the baseline. Between the recovery 1 and recovery 2 sampling times, for both the continuous ( 0.3 -fold; $P=0.08$ ) and transient (0.4-fold; $P=0.02)$ feeding models, a decrease in MCT2 expression was found. The NHE2 was similar in fold change for the high-grain and the recovery 1 sampling regardless of feeding model $(P>0.71)$. However, in the transient feeding model, NHE2 increased by $46 \%$ in the second recovery sampling compared with the first recovery sampling $(P=0.04)$. Similarly, NHE3 also increased between the high-grain feeding and the long-term recovery $(P<0.05)$ in both the continuous (0.44-fold) and transient (0.67-fold) models. Relative to the baseline, DRA expression increased by 1.6 -fold in the transient model when sampled at $105 \mathrm{~d}$ in the forage recovery feeding $(P=0.01)$. Whereas standard variation in $D R A$ gene expression was higher $(\mathrm{SEM}=$ 0.27 ), the variation between sampling days was not due to any outliers. The $C D 14$ showed a quadratic change in gene expression relative to the baseline with an increase from the high-grain feeding to the short-term recovery $1(P=0.04)$ and then a decrease at 105-d long-term recovery 2 sampling $(P=0.01$; Figure 7$)$.

Linear canonical discriminant analysis of all genes was performed to determine relationships between sampling days and gene targets (Figure 8), with the first 2 eigenvectors representing $73.7 \%$ of the variation between samples. Unlike for the analysis of genera, canonical analysis of gene targets showed that sam-

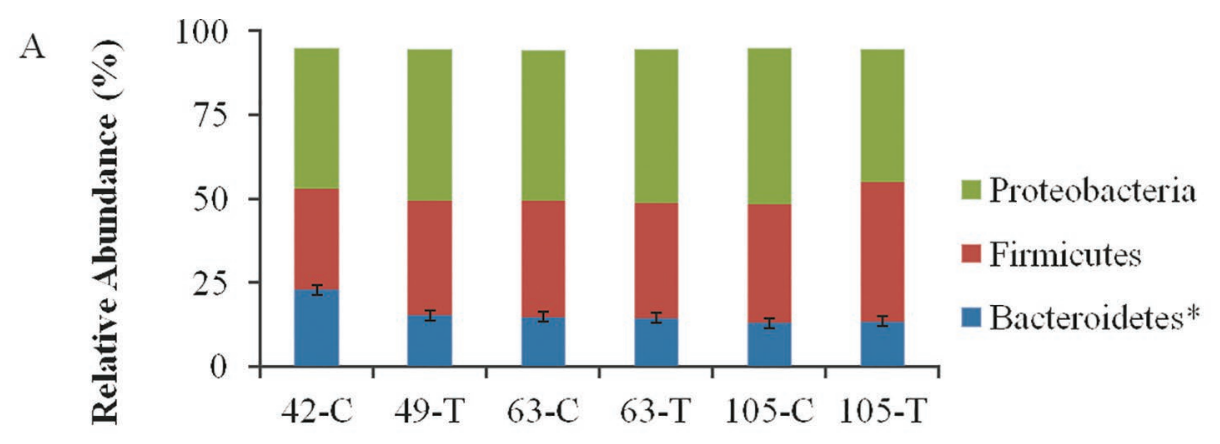

B

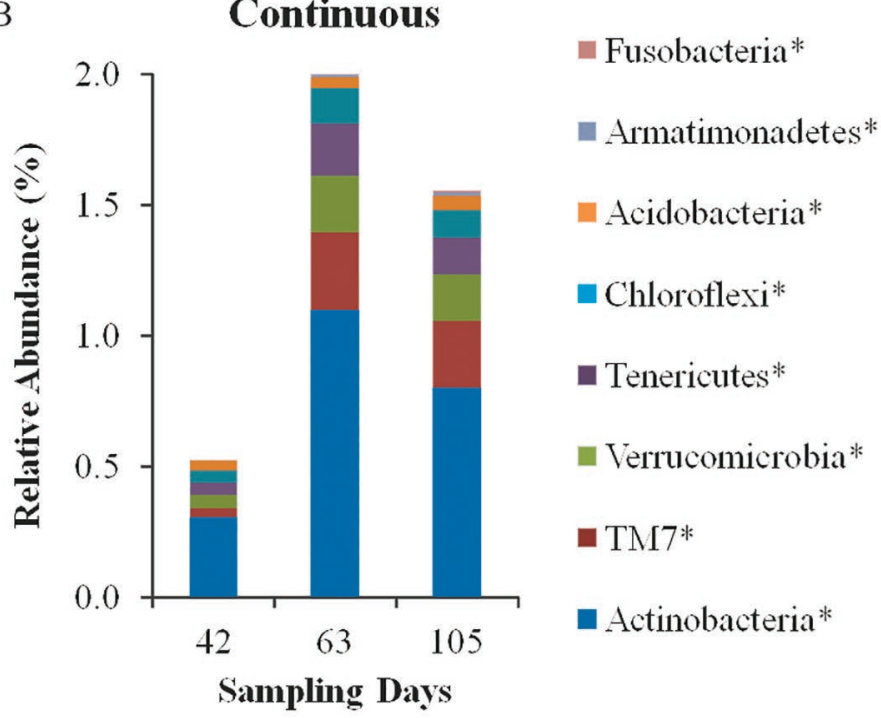

Transient

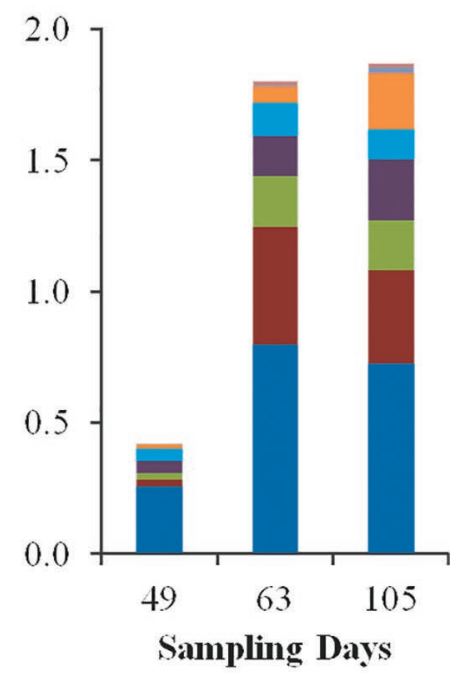

Figure 4. Relative abundance of the major (A) and minor phyla in the continuous (C) feeding model and the transient (T) feeding model (B) relative to sampling time point. *Phyla with an asterisk are significantly different $(P \leq 0.05)$ based on sampling day. 


\section{High Grain Feeding}

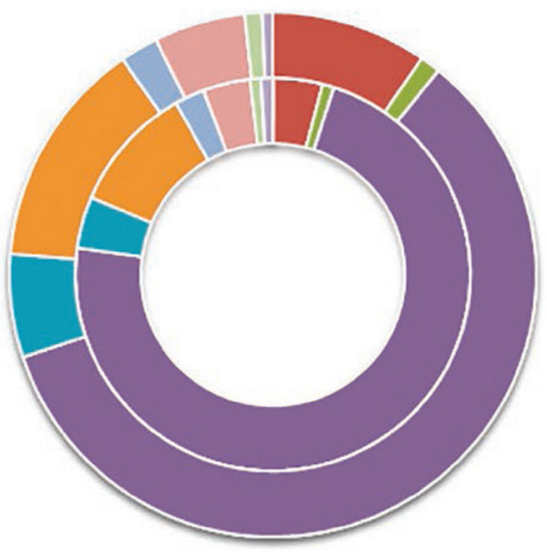

\section{Recovery 1}

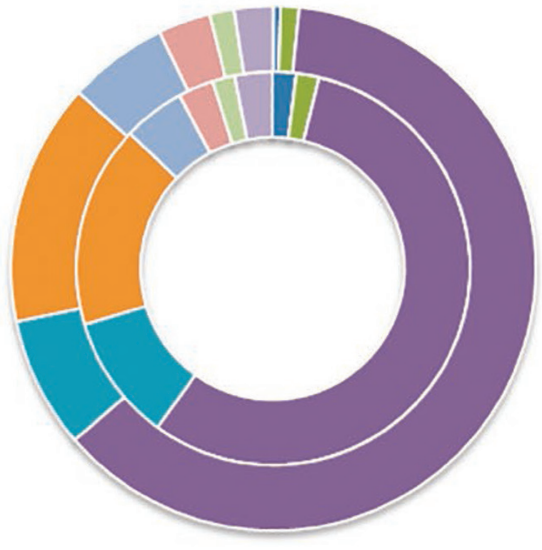

\section{Recovery 2}

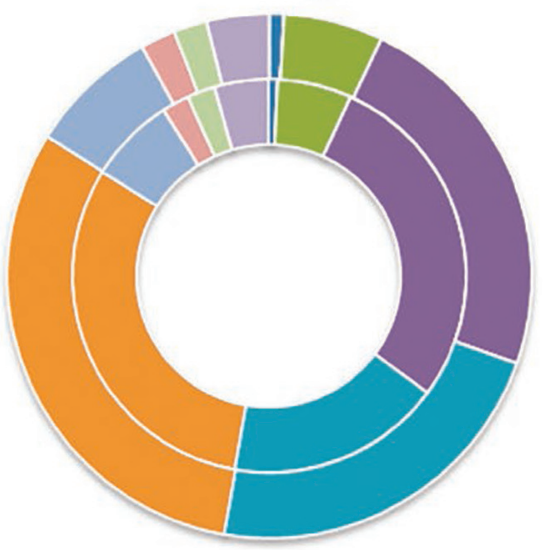

- Actinobacteria:Actinobaculum

- Actinobacteria:Bifidobacterium

- Actinobacteria:Gordonibacter.

- Bacteroidetes:Anaerophaga

- Bacteroidetes:Anaerorhabdus

- Bacteroidetes: Ornithobacterium

- Bacteroidetes:Petrimonas

- Bacteroidetes:Psendozobellia

Chloroflexi:Bellilinea

Tenericutes:Asteroleplasma

Figure 5. Relative abundance of the genera with an effect of sampling day $(P \leq 0.05)$ from significantly affected phyla with a relative abundance $>0.09 \%$ sampled during the high-grain feeding, recovery $1(63 \mathrm{~d})$, and recovery $2(105 \mathrm{~d})$. The inner ring is for the continuous model, and the outer ring is for the transient model. Additional genera with a significant effect of sampling day but relative abundance $<0.09 \%$ included Aldercreutzia, Corynebacterium, and Enterrohabdus from the phyla Actinobacteria, Fontibacter, Leadbetterella, Persicitalea, and Siphonobacter from the phlya Bacteroidetes; as well as Akkermansia and Coraliomargarita from the Verrucomicrobia phyla. 


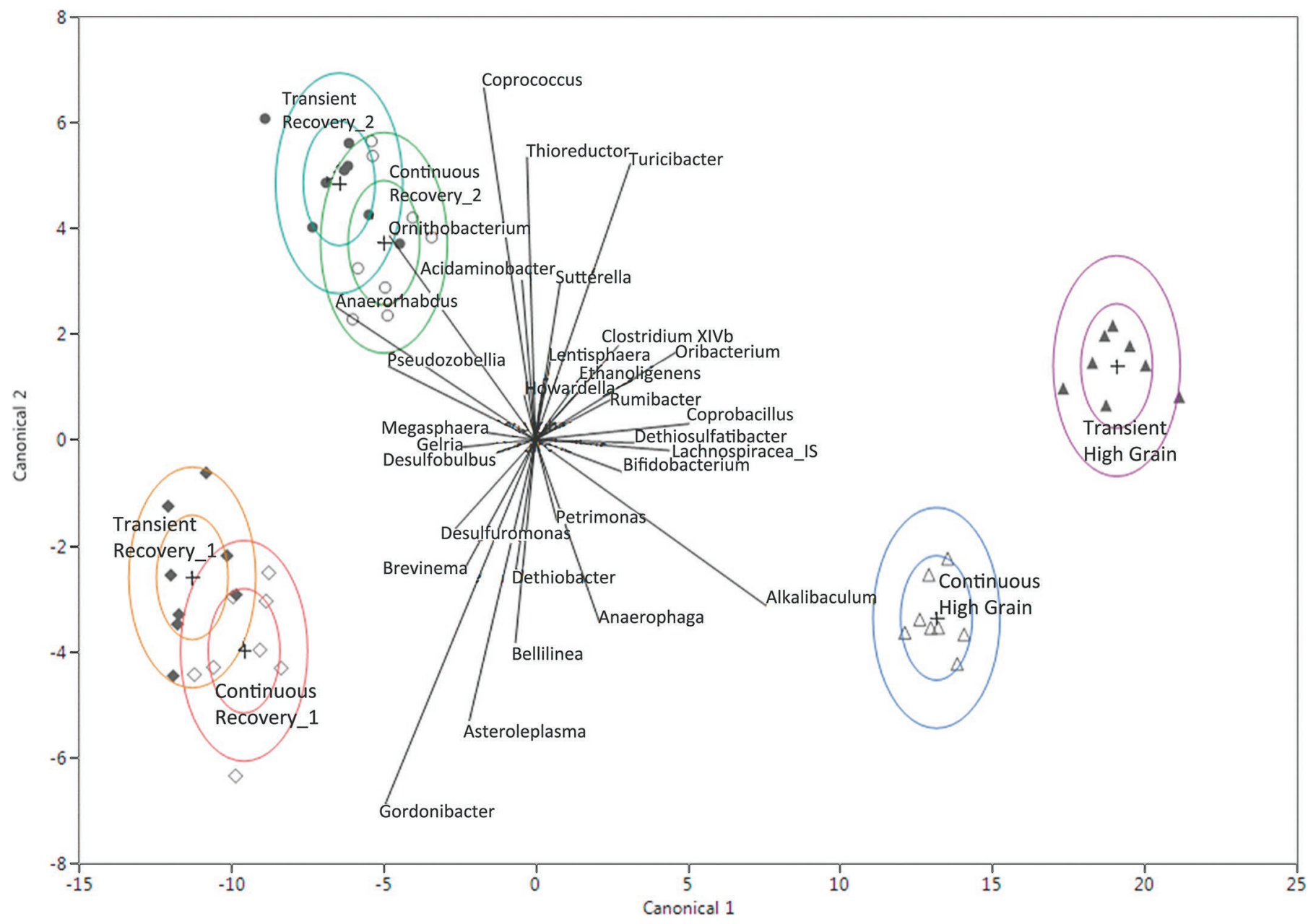

Figure 6. Canonical component analysis of genera affected by sampling day in relation to the feeding model (transient vs. continuous) and sampling time [high-grain, $42 \mathrm{~d}$ (continuous) or $49 \mathrm{~d}$ (transient); recovery_1, $63 \mathrm{~d}$; recovery_2, $105 \mathrm{~d}$ ].

pling days for both models did not cluster together. The recovery phase for the continuous and transient models clustered independently. The high-grain feeding for the transient model clustered apart from the other samplings. The largest variability was seen in the ratios between MCT1 and CDSN and therefore these genes have the strongest reciprocal ratio relationship. Groups of genes (barrier function, $\mathrm{pH}$ regulation, and SCFA uptake) did not cluster together despite clustering of samples together.

\section{Correlation Analysis}

Pearson correlation analysis of significantly affected bacterial genera, relative absorption parameters, and gene expression targets is shown in Table 2. Most correlations tended to be low to moderate. The strongest correlation was found between NHE3 and Coprococcus spp. $(\mathrm{r}=0.67)$. Coprococcus had positive correlations with DRA, MCT1, and NHE2 as well as negative correlations to absorption parameters. This trend was also seen for Alkalibaculum, Anaerorhabdus, and Dethiobacter spp. Interestingly, MCT2 had no correlations to any uptake parameters or genera. The inverse of this was only seen with Desulfobulbus spp. where absorption parameters were negatively correlated and NHE2 and NHE3 were positively correlated. The only gene target with a significant correlation to the absorption parameters was $D R A$. Correlation between genera and $D R A$ was positive and the correlation between absorption and DRA was negative (Table 2).

\section{DISCUSSION}

The present study aimed at determining the effect of either a continuous or transient feeding model on the 


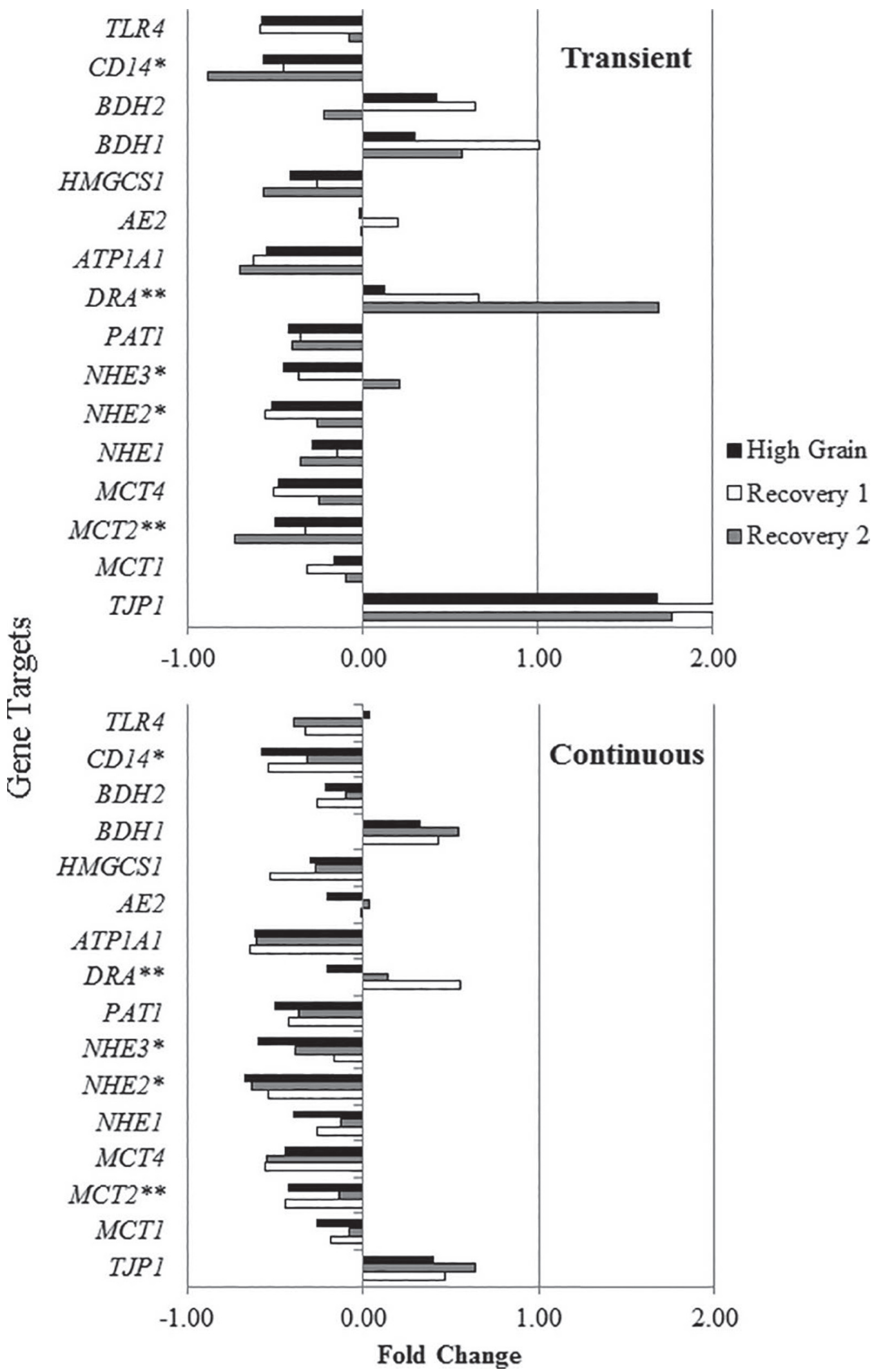

Figure 7. Fold change in significantly affected genes relative to sampling day in the continuous feeding model (A) and the transient feeding model (B). Gene targets analyzed with quantitative real-time PCR method (qPCR). *Significant effect $(P<0.05)$ of sampling day on gene expression within a specific feeding model. ${ }^{* *}$ Trend toward significant effect of sampling day $(0.10<P>0.05)$. 
reticuloruminal absorption capacity, epithelial bacteria, and host gene expression during and after high-grain feeding. We previously reported that the transient grain feeding induced more severe SARA conditions. Specifically, the daily mean ruminal $\mathrm{pH}$ at the end of high-grain feeding of cows in the continuous model was 6.15 , whereas it was 5.93 for the transient group (Pourazad et al., 2016). Furthermore, the duration of $\mathrm{pH}$ suppression below 5.8 in the transient feeding model
(500 min) was twice as long as in the continuous feeding model (220 min; Pourazad et al., 2016). The lower severity of SARA found with the continuous feeding model was linked to elevated SCFA absorption (Qumar et al., 2016), although no clear effect of grain feeding model was seen for endotoxin production or metabolic responses (Qumar et al., 2017). The persistence in high-grain feeding also promoted restoration of ruminal fibrolytic capability during the grain feeding (Pourazad

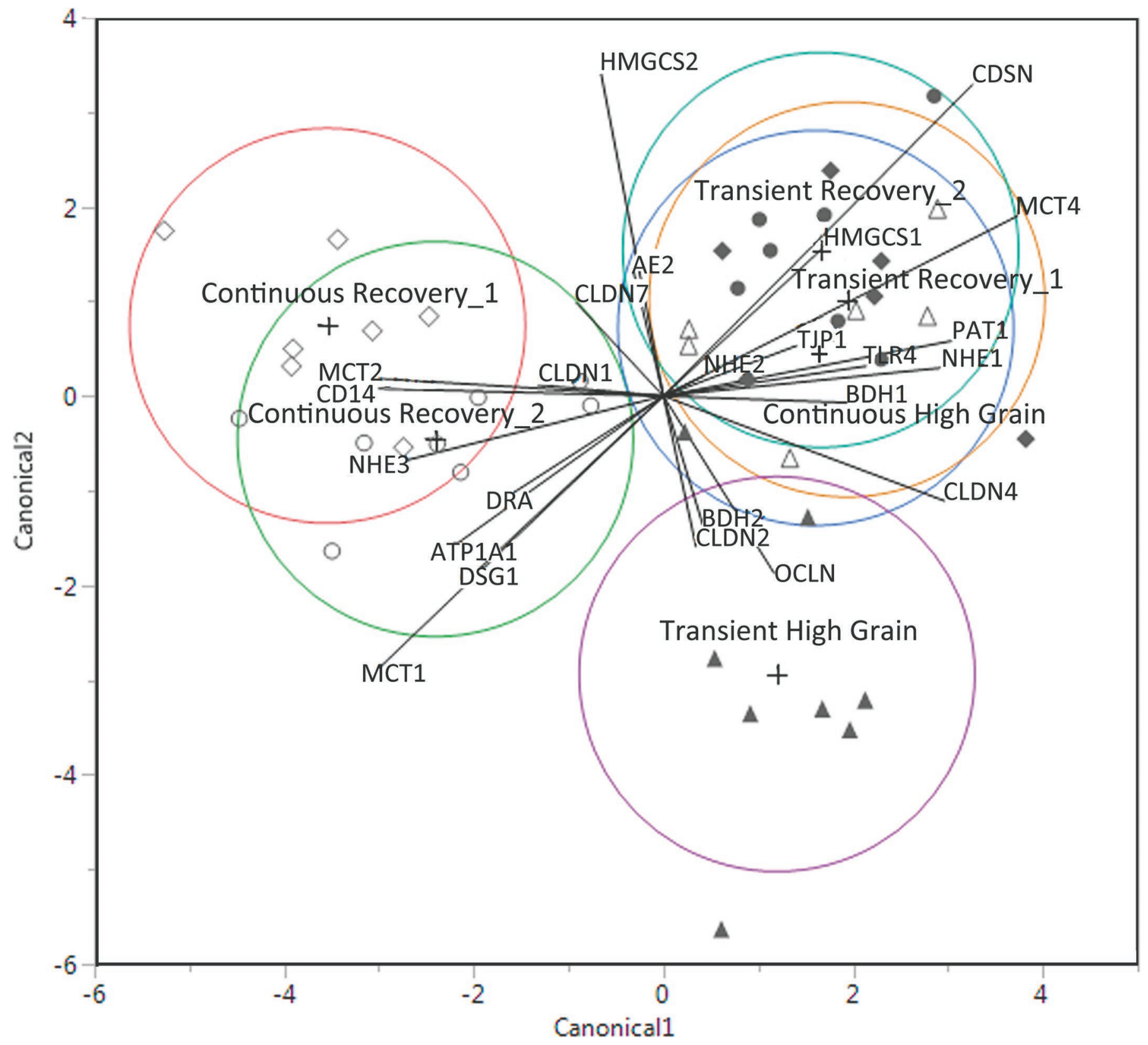

Figure 8. Canonical component analysis of all gene targets in relation to the feeding model (transient vs. continuous) and sampling time [high-grain, $42 \mathrm{~d}$ (continuous) or $49 \mathrm{~d}$ (transient); recovery_1, $63 \mathrm{~d}$; recovery_2, $105 \mathrm{~d}$ ]. 
et al., 2016). Additionally, the rumen epithelial bacteria were shown to be less stable after a week of forage feeding in the transient feeding (Wetzels et al., 2016), but overall less diverse after a 4 -wk continuous high-grain feeding compared with the start of high-grain feeding (Wetzels et al., 2017). Certainly, rumen adaptation to high-grain diets is time dependent (Dirksen, 1985) and damage to the rumen epithelium would depend on the duration and severity of decreased $\mathrm{pH}$ (Steele et al., 2011). It was not known whether the high-grain diet and the feeding persistency have a long-lasting effect on the reticulorumen epithelial adaptation and the associated bacteria during time of recovery from highgrain feeding. As previously reported (Schurmann et al., 2014; Schwaiger et al., 2013), we found that the high-grain feeding promoted the SCFA absorption and the absorption declined during forage feeding. Because morphological adaptation requires 6 to 8 wk of diet adaptation to reach the maximum changes (Penner et al., 2010; Steele et al., 2011; Zhang et al., 2013a), it is also likely that the associated changes for recovery to forage feeding could also require several weeks. Since at the 63 d (2-wk recovery) a sustained capacity to absorb SCFA was found, but not seen at $105 \mathrm{~d}$ (8-wk recovery), the results of the present study would indicate that a full adaption to forage diet occurs between 3 and 8 wk of continuous forage feeding.

\section{Epithelial Bacterial Community}

In agreement with previous studies, the diversity of the rumen epithelial bacterial community increased in diversity with forage feeding (Petri et al., 2013a). The increase in diversity showed a linear pattern from the last high grain sampling to 8-wk forage feeding in both feeding models. Similar to the SCFA absorption, a forage-only interruption in the transient model did not allow a stable adaptation of the ruminal epithelium as well as the bacteria at the 49-d sampling. Consistent with our results, Dohme et al., (2008) demonstrated that the severity of low $\mathrm{pH}$ resulting from a grain challenge worsens with repeated challenges, and hypothesized that the unstable ruminal milieu due to grain challenges caused instability of the ruminal microflora, and potentially decreased the absorptive capacity of the ruminal epithelium. However, previous studies looking at microbiome and epithelial recovery used shorter recovery periods (Petri et al., 2013a; Zhang et al., 2013b).

\section{Host Gene Expression}

Compared with high-grain feeding, forage feeding lowers DMI, slows down the release and production of SCFA, and shifts the composition of SCFA, resulting in increased $\mathrm{pH}$ and decreased osmolarity of the ruminal fluid (Aschenbach et al., 2011). Previous research shows epithelial adaptation to increased SCFA production is due to increases in transporter expression (Andersen et al., 1999), which would imply that decreased SCFA production associated with a forage diet would result in decreased transporter expression. One such transporter is $M C T 1$, which is involved in protein-mediated flux of SCFA (Graham et al., 2007; Laarman et al., 2016) and intracellular pH homeostasis (Müller et al., 2000). In

Table 2. Significant Pearson correlation coefficients for genera, gene expression, and absorption parameters

\begin{tabular}{|c|c|c|c|c|c|c|c|c|c|}
\hline \multirow[b]{2}{*}{ Genera } & \multicolumn{4}{|c|}{ Relative absorption } & \multirow[b]{2}{*}{$D R A^{1}$} & \multirow[b]{2}{*}{$M C T 1^{2}$} & \multirow[b]{2}{*}{ NHE $2^{3}$} & \multirow[b]{2}{*}{ NHE3 } & \multirow[b]{2}{*}{$T J P 1^{4}$} \\
\hline & Acetate & Propionate & Butyrate & Total SCFA ${ }^{5}$ & & & & & \\
\hline Alkalibaculum & -0.42 & -0.43 & -0.45 & -0.43 & 0.43 & 0.42 & 0.40 & 0.47 & $\mathrm{NS}^{6}$ \\
\hline Anaerorhabdus & -0.56 & -0.54 & -0.54 & -0.56 & 0.59 & 0.30 & 0.45 & 0.52 & $\mathrm{NS}$ \\
\hline Coprobacillus & -0.49 & -0.45 & -0.45 & -0.48 & 0.50 & NS & 0.40 & 0.45 & NS \\
\hline Coprococcus & -0.32 & -0.33 & -0.33 & -0.33 & 0.56 & 0.51 & 0.62 & 0.67 & NS \\
\hline Desulfobulbus & 0.35 & 0.32 & 0.38 & 0.35 & NS & -0.41 & -0.33 & NS & 0.30 \\
\hline Dethiobacter & -0.41 & -0.39 & -0.37 & -0.40 & 0.44 & 0.34 & 0.35 & 0.34 & NS \\
\hline Ethanoligenens & -0.49 & -0.49 & -0.47 & -0.49 & 0.44 & NS & NS & NS & NS \\
\hline Gelria & -0.51 & -0.50 & -0.46 & -0.51 & 0.44 & NS & 0.37 & 0.35 & NS \\
\hline Ornithobacterium & -0.52 & -0.51 & -0.50 & -0.52 & 0.43 & 0.13 & NS & 0.40 & NS \\
\hline Petrimonas & NS & NS & NS & NS & NS & NS & NS & NS & 0.52 \\
\hline$D R A$ & -0.49 & -0.42 & -0.41 & -0.46 & NS & NS & NS & NS & NS \\
\hline
\end{tabular}

${ }^{1} D R A=$ downregulated in adenoma.

${ }^{2} M C T 1=$ monocarboxylate transport 1.

${ }^{3}$ NHE2 $/$ NHE3 $=$ sodium/hydrogen exchanger isoforms 2 and 3.

${ }^{4}$ TJP1 = zona occludens 1.

${ }^{5}$ Total SCFA $=$ short-chain fatty acids in percentage.

${ }^{6} \mathrm{NS}=$ Pearson correlation coefficient is statistically not significant according to Tukey's honestly significant difference method. 
the current study, we found the decreases in expression of $M C T 1$, as well as MCT2 and MCT4, relative to the baseline in all sampling days even during the high-grain feeding. These data correspond to previously published data from Laarman et al. (2016), but bring into question the specific role of MCT1 in both the short and long term under high-grain feeding (Dohme et al., 2008; Laarman et al., 2016). Despite similarities to previously published data, it is critical to assess that changes in nutrient and ion transporters in our study are relative to the location of tissue sampled and the variation that occurs with multiple samplings. Furthermore, our data show that despite $8 \mathrm{wk}$ of forage feeding, which is thought to be a sufficient amount of time for rumen adaptation to diet (Bevans et al.., 2005), alterations in the gene expression profiles compared with baseline could still be seen. It is important to note that the relative expression of mRNA is used to indicate the molecular response of the host to dietary changes but does not necessarily reflect the amount of functional protein present in the cell (Steele et al., 2012). Therefore, further study is required to elucidate the role of the functional protein and molecular gene adaptation of the rumen epithelium with relation to increased SCFA.

Of the 3 bicarbonate exchangers analyzed in this study (DRA, AE2, and PAT1), significant upregulation in the expression of the $D R A$ (Yan et al., 2014) was seen in response to forage feeding phase and more predominantly in the transient feeding model. Yan et al. (2014) reported an upregulation of the gene expression for bicarbonate exchangers including $D R A$ under reduced $\mathrm{pH}$ and highly correlated with SCFA produced in the rumen. However, the expression of DRA in our study continued to increase with the highest expression levels occurring in the recovery phase at $105 \mathrm{~d}$ of sampling. As a sulfate anion transporter, $D R A$ mediates chloride and bicarbonate exchange and previous research has shown a potential binding between the gene product of DRA and NHE3, linking bicarbonate and sodium/ hydrogen exchange in the intestine (Lamprecht et al., 2002). This is supported by a similar trend between the 2 gene targets with regard to patterns of expression.

The rumen epithelial barrier is a complex, functional syncytium of cells with intercellular tight junctions that regulate the permeability (Graham and Simmons, 2005) and prevent the translocation of LPS and other toxins (Minuti et al., 2015). Compromised barrier function has been associated with the release of free endotoxin (LPS; Emmanuel et al., 2007), which could have both local and systemic effects on inflammation (Emmanuel et al., 2008). However, in the current study, the relative gene expression in rumen papillae showed no significant changes in the expression of tight junc- tion proteins after 4 wk of high-grain feeding as well as in both short- and long-term recovery forage feeding. However, numerical increases in the fold change of gene expression for TJP1 with more than 2 times the expression in the transient feeding model compared with the continuous would indicate that changes are occurring in the rumen papillae due to the feeding of high grain that may not have been captured with the current sampling program. The current data for gene expression of tight junction proteins are supported by the companion study (Qumar et al., 2017) showing that no systemic inflammation was developed despite the heavy load of LPS in both models. This might be related to the level of $\mathrm{pH}$ decrease induced by our high-grain feeding, which was less severe than the $\mathrm{pH}$ capable of triggering hyperpermeability of rumen tissues in response to LPS (Emmanuel et al., 2008). In line with that, the relative expression of $C D 14$ was found to decrease with the onset of high-grain feeding, but this decrease continued throughout the recovery period with the lowest expression occurring at $105 \mathrm{~d}$ of sampling regardless of feeding model. This was not true for TLR 4, which increased in expression in the continuous model at $49 \mathrm{~d}$ and then decreased during the recovery phases. The alterations in the expression of LPS ligating proteins such as TLR4 and $C D 14$ could indicate an adaptive response of the animal to extended exposure to increased levels of LPS.

\section{Correlations Between Host, Epithelial Bacteria, and SCFA Absorption}

Interestingly, the linear canonical discriminant analysis shows a clear separation between both models for gene expression targets in the recovery phases even though cows in both models were fed identically after the different models of grain feeding. This would indicate that the high-grain feeding model has an effect on the ability of the gene expression to recover. In addition, the high-grain feeding for the transient model clustered apart from the other samplings, indicating that the gene expression at $49 \mathrm{~d}$ in the transient model was affected differently than in the continuous model. Interestingly, from those bacteria that showed a significant effect of sampling day, many that were increased (Alkalibaculum, Coprobacillus, Coprococcus, Gelria, Ethanoligenes, and Dethiobacter) in the forage feeding period were gram-positive bacteria and not the LPSproducing gram-negative bacteria. Therefore, the role of the rumen epithelial bacteria in host gene expression with regard to commensal versus opportunistic pathogens requires further research and the development of reliable assays for other TLR targets such as TLR2. Of those genera found to be significantly different based 
on sampling day Alkalibaculum, Coprococcus, and Dethiobacter had low to moderate Pearson correlations (34 $<\mathrm{r}>67)$ to DRA, MCT1, NHE2, and NHE3, and all correlated negatively to SCFA absorption parameters. The increase in relative abundance, combined with a decrease in SCFA absorption with increased time on forage feeding in the recovery phase, would indicate that the DRA and NHE3 are responsible for rumen cellular $\mathrm{pH}$ balance under normal rumen $\mathrm{pH}$ conditions.

Additionally, looking at the changes in other proteins within the inflammation cascade in the rumen epithelium may give more insight into the role changes that the epithelial bacterial community has on host cells.

\section{CONCLUSIONS}

The present study demonstrates that high-grain feeding regimen can affect the adaptation of the reticuloruminal epithelium to absorb SCFA, and that changes in the diet affect the rumen epithelial bacteria and the host gene expression independently but simultaneously. Patterns of gene expression differed between feeding models but the epithelial bacterial community structure was more closely associated with sampling day after the challenge than the feeding model used. Despite high-grain feeding, no significant changes in barrier function or LPS receptors were found that would indicate minimal ruminal dysbiosis. However, the use of a transient feeding model had more variable effects on host gene expression. Further research looking at the associated epimural community in correlation with the host protein expression will provide better insight into the host-microbe interaction in relation to high-grain feeding and long-term recovery.

\section{ACKNOWLEDGMENTS}

The authors thank W. Pohl and the staff of the research station "Kremesberg" at the Vetmeduni, Vienna, Austria, for their assistance throughout the animal trial. A. Dockner, M, Wild, M. Salzmann, and S. Sharma (Institute of Animal Nutrition and Functional Plant Compounds, Vetmeduni, Vienna, Austria) are highly appreciated for their support and expertise during the experiment. The authors also recognize the contribution of P. Pourazad (Vetmeduni, Vienna, Austria) and F. Klevenhusen (Vetmeduni, Vienna, Austria) in the running of the trial, A. Sener (Vetmeduni, Vienna, Austria) for her significant work in the laboratory, and E. Mann and Stephan Schmitz-Esser (Institute for Milk Hygiene, Milk Technology and Food Science, Vetmeduni, Vienna, Austria) for their assistance during the data analysis. The authors also thank the Vetmeduni Post-Doc Programme for funding support.

\section{REFERENCES}

Andersen, C. L., J. L. Jensen, and T. F. Ørntoft. 2004. Normalization of real-time quantitative reverse transcription-PCR data: A model-based variance estimation approach to identify genes suited for normalization, applied to bladder and colon cancer data sets. Cancer Res. 64:5245-5250. https://doi.org/10.1158/0008-5472 .CAN-04-0496.

Andersen, J. B., J. Sehested, and K. L. Ingvartsen. 1999. Effect of dry cow feeding strategy on rumen $\mathrm{pH}$, concentration of volatile fatty acids and rumen epithelium development. Acta Agric. Scand. A Anim. Sci. 49:149-155. https://doi.org/10.1080/090647099424051.

Aschenbach, J. R., G. B. Penner, F. Stumpff, and G. Gäbel. 2011. Ruminant nutrition symposium: Role of fermentation acid absorption in the regulation of ruminal pH. J. Anim. Sci. 89:1092-1107. https: //doi.org/10.2527/jas.2010-3301.

Bevans, D. W., K. A. Beauchemin, K. S. Schwartzkopf-Genswein, J. J. McKinnon, and T. A. Mcallister. 2005. Effect of rapid or gradual grain adaptation on subacute acidosis and feed intake by feedlot cattle. J. Anim. Sci. 83:1116-1132. https://doi.org/10.2527/2005 $.8351116 \mathrm{x}$.

Dirksen, G. 1985. The rumen acidosis complex-Recent knowledge and experiences (1). A review. Tierarztl. Prax. 13:501-512.

Dirksen, G., H. G. Liebich, G. Brosi, H. Hagemeister, and E. Mayer. 1984. Morphologie der pansenschleimhaut und fettsäureresorption beim rind-Bedeutende faktoren für gesundheit und leistung. Zentralblatt für Veterinärmedizin Reihe A 31:414-430. https://doi .org/10.1111/j.1439-0442.1984.tb01300.x.

Dohme, F., T. J. DeVries, and K. A. Beauchemin. 2008. Repeated ruminal acidosis challenges in lactating dairy cows at high and low risk for developing acidosis: Ruminal pH. J. Dairy Sci. 91:35543567. https://doi.org/10.3168/jds.2008-1264.

Emmanuel, D. G. V., S. M. Dunn, and B. N. Ametaj. 2008. Feeding high proportions of barley grain stimulates an inflammatory response in dairy cows. J. Dairy Sci. 91:606-614. https://doi.org/10 $.3168 /$ jds.2007-0256.

Emmanuel, D. G. V., K. L. Madsen, T. A. Churchill, S. M. Dunn, and B. N. Ametaj. 2007. Acidosis and lipopolysaccharide from Escherichia coli B:055 cause hyperpermeability of rumen and colon tissues. J. Dairy Sci. 90:5552-5557. https://doi.org/10.3168/ jds.2007-0257.

Gao, X., and M. Oba. 2016. Characteristics of dairy cows with a greater or lower risk of subacute ruminal acidosis: Volatile fatty acid absorption, rumen digestion, and expression of genes in rumen epithelial cells. J. Dairy Sci. 99:8733-8745. https://doi.org/10.3168/ jds.2016-11570.

Graham, C., I. Gatherar, I. Haslam, M. Glanville, and N. L. Simmons. 2007. Expression and localization of monocarboxylate transporters and sodium/proton exchangers in bovine rumen epithelium. Am. J. Physiol. Regul. Integr. Comp. Physiol. 292:R997-R1007. https: //doi.org/10.1152/ajpregu.00343.2006.

Graham, C., and N. L. Simmons. 2005. Functional organization of the bovine rumen epithelium. Am. J. Physiol. Regul. Integr. Comp. Physiol. 288:R173-R181. https://doi.org/10.1152/ajpregu.00425 .2004 .

Gui, H., and Z. Shen. 2016. Concentrate diet modulation of ruminal genes involved in cell proliferation and apoptosis is related to combined effects of short-chain fatty acid and $\mathrm{pH}$ in rumen of goats. J. Dairy Sci. 99:6627-6638. https://doi.org/10.3168/jds.2015-10446.

Hinkle, D. E., W. Wiersma, and S. G. Jurs. 2003. Applied Statistics for the Behavioral Sciences. 5th ed. Houghton Mifflin, Boston, MA.

Khafipour, E., D. O. Krause, and J. C. Plaizier. 2009a. Alfalfa pelletinduced subacute ruminal acidosis in dairy cows increases bacterial endotoxin in the rumen without causing inflammation. J. Dairy Sci. 92:1712-1724. https://doi.org/10.3168/jds.2008-1656. 
Khafipour, E., S. Li, J. C. Plaizier, and D. O. Krause. 2009b. Rumen microbiome composition determined using two nutritional models of subacute ruminal acidosis. Appl. Environ. Microbiol. 75:71157124. https://doi.org/10.1128/AEM.00739-09.

Kleen, J. L., G. A. Hooijer, J. Rehage, and J. P. Noordhuizen. 2003. Subacute ruminal acidosis (SARA): A review. J. Vet. Med. A Physiol. Pathol. Clin. Med. 50:406-414. https://doi.org/10.1111/ asj.12415.

Kozich, J. J., S. L. Westcott, N. T. Baxter, S. K. Highlander, and P. D. Schloss. 2013. Development of a dual-index sequencing strategy and curation pipeline for analyzing amplicon sequence data on the MiSeq Illumina sequencing platform. Appl. Environ. Microbiol. 79:5112-5120. https://doi.org/10.1128/AEM.01043-13.

Laarman, A. H., L. Dionissopoulos, O. AlZahal, M. A. Steele, S. L. Greenwood, J. C. Matthews, and B. W. McBride. 2013. Butyrate supplementation affects mRNA abundance of genes involved in glycolysis, oxidative phosphorylation and lipogenesis in the rumen epithelium of Holstein dairy cows. Am. J. Anim. Vet. Sci. 8:239. https://doi.org/10.3844/ajavsp.2013.239.245.

Laarman, A. H., R. L. A. Pederzolli, K. M. Wood, G. B. Penner, and B. W. McBride. 2016. Effects of subacute ruminal acidosis and low feed intake on short-chain fatty acid transporters and flux pathways in Holstein steers. J. Anim. Sci. 94:3729-3737. https:// doi.org/10.2527/jas.2016-0638.

Lamprecht, G., A. Heil, S. Baisch, E. Lin-Wu, C. C. Yun, H. Kalbacher, M. Gregor, and U. Seidler. 2002. The down regulated in adenoma (dra) gene product binds to the second PDZ domain of the NHE3 kinase A regulatory protein (E3KARP), potentially linking intestinal $\mathrm{Cl}$-/HCO3- exchange to $\mathrm{Na}+/ \mathrm{H}+$ exchange. Biochemistry 41:12336-12342. https://doi.org/10.1021/bi0259103.

McCann, J. C., S. Luan, F. C. Cardoso, H. Derakhshani, E. Khafipour, and J. J. Loor. 2016. Induction of subacute ruminal acidosis affects the ruminal microbiome and epithelium. Front. Microbiol. 18:701. https://doi.org/10.3389/fmicb.2016.00701.

Minuti, A., A. Palladino, M. J. Khan, S. Alqarni, A. Agrawal, F. Piccioli-Capelli, F. Hidalgo, F. C. Cardoso, E. Trevisi, and J. J. Loor. 2015. Abundance of ruminal bacteria, epithelial gene expression, and systemic biomarkers of metabolism and inflammation are altered during the peripartal period in dairy cows. J. Dairy Sci. 98:8940-8951. https://doi.org/10.3168/jds.2015-9722.

Müller, F., J. R. Aschenbach, and G. Gäbel. 2000. Role of $\mathrm{Na}^{+} / \mathrm{H}^{+}$ exchange and $\mathrm{HCO}_{3}{ }^{-}$transport in $\mathrm{pH}_{\mathrm{i}}$ recovery from intracellular acid load in cultured epithelial cells of sheep rumen. J. Comp. Physiol. B 170:337-343. https://doi.org/10.1007/s003600000107.

Nocek, J. E., J. G. Allman, and W. P. Kautz. 2002. Evaluation of an indwelling ruminal probe methodology and effect of grain level on diurnal $\mathrm{pH}$ variation in dairy cattle. J. Dairy Sci. 85:422-428. https://doi.org/10.3168/jds.S0022-0302(02)74090-3.

Penner, G. B., M. Oba, G. Gäbel, and J. R. Aschenbach. 2010. A single mild episode of subacute ruminal acidosis does not affect ruminal barrier function in the short term. J. Dairy Sci. 93:48384845. https://doi.org/10.3168/jds.2010-3406.

Penner, G. B., M. A. Steel, J. R. Aschenbach, and B. W. McBride. 2011. Ruminant Nutrition Symposium: Molecular adaptation of ruminal epithelia to highly fermentable diets. J. Anim. Sci. 89:1108-1119. https://doi.org/10.2527/jas.2010-3378.

Petri, R. M., M.-T. Kleefisch, B. U. Metzler-Zebeli, Q. Zebeli, and F. Klevenhusen. 2018. Changes in the rumen epithelial microbiota of cattle and host gene expression in response to alterations in dietary carbohydrate composition. Appl. Environ. Microbiol. 84:e00384-e00418. https://doi.org/10.1128/aem.00384-18.

Petri, R. M., P. Pourazad, R. Khiaosa-Ard, F. Klevenhusen, B. U. Metzler-Zebeli, and Q. Zebeli. 2017. Temporal dynamics of in situ fiber-adherent bacterial community under ruminal acidotic conditions determined by $16 \mathrm{~S}$ rRNA gene profiling. PLoS One 12:e0182271. https://doi.org/10.1371/journal.pone.0182271.

Petri, R. M., T. Schwaiger, G. B. Penner, K. A. Beauchemin, R. J. Forster, J. J. McKinnon, and T. A. McAllister. 2013a. Changes in the rumen epimural bacterial diversity of beef cattle as affected by diet and induced ruminal acidosis. Appl. Environ. Microbiol. 79:3744-3755. https://doi.org/10.1128/AEM.03983-12.
Petri, R. M., T. Schwaiger, G. B. Penner, K. A. Beauchemin, R. J. Forster, J. J. McKinnon, and T. A. McAllister. 2013b. Characterization of the core rumen microbiome in cattle during transition from forage to concentrate as well as during and after an acidotic challenge. PLoS One 8:e83424. https://doi.org/10.1371/journal .pone.0083424.

Pfaffl, M. W. 2001. A new mathematical model for relative quantification in real-time RT-PCR. Nucleic Acids Res. 29:e45. https://doi .org/10.1093/nar/29.9.e45.

Plaizier, J. C., D. O. Krause, G. N. Gozho, and B. W. McBride. 2008. Subacute ruminal acidosis in dairy cows: The physiological causes, incidence and consequences. Vet. J. 176:21-31. https://doi.org/10 $.1016 /$ j.tvjl.2007.12.016.

Pourazad, P., R. Khiaosa-Ard, M. Qumar, S. U. Wetzels, F. Klevenhusen, B. U. Metzler-Zebeli, and Q. Zebeli. 2016. Transient feeding of a concentrate-rich diet increases the severity of subacute ruminal acidosis in dairy cattle. J. Anim. Sci. 94:726-738. https://doi.org/ 10.2527 /jas.2015-9605.

Qumar, M., R. Khiaosa-ard, F. Klevenhusen, J. C. Plaizier, and Q. Zebeli. 2017. Gastrointestinal endotoxin and metabolic responses in cows fed and recovered from two different grain-rich challenges. Livest. Sci. 203:120-123. https://doi.org/10.1016/j.livsci.2017.07 .015 .

Qumar, M., R. Khiaosa-ard, P. Pourazad, S. U. Wetzels, F. Klevenhusen, W. Kandler, J. R. Aschenbach, and Q. Zebeli. 2016. Evidence of in vivo absorption of lactate and modulation of short chain fatty acid absorption from the reticulorumen of non-lactating cattle fed high concentrate diets. PLoS One 11:e0164192. https://doi.org/10 .1371/journal.pone.0164192.

Schurmann, B. L., M. E. Walpole, P. Górka, J. C. H. Ching, M. E. Loewen, and G. B. Penner. 2014. Short-term adaptation of the ruminal epithelium involves abrupt changes in sodium and shortchain fatty acid transport. Am. J. Physiol. Regul. Integr. Comp. Physiol. 307:R802-R816. https://doi.org/10.1152/ajpregu.00035 .2014 .

Schwaiger, T., K. A. Beauchemin, and G. B. Penner. 2013. Duration of time that beef cattle are fed a high-grain diet affects the recovery from a bout of ruminal acidosis: Short-chain fatty acid and lactate absorption, saliva production, and blood metabolites. J. Anim. Sci. 91:5743-5753. https://doi.org/10.2527/jas.2013-6472.

Steele, M. A., J. Croom, M. Kahler, O. AlZahal, S. E. Hook, K. Plaizier, and B. W. McBride. 2011. Bovine rumen epithelium undergoes rapid structural adaptations during grain-induced subacute ruminal acidosis. Am. J. Physiol. Regul. Integr. Comp. Physiol. 300:R1515-R1523. https://doi.org/10.1152/ajpregu.00120.2010.

Steele, M. A., L. Dionissopoulos, O. AlZahal, J. Doelman, and B. W. McBride. 2012. Rumen epithelial adaptation to ruminal acidosis in lactating cattle involves the coordinated expression of insulin-like growth factor-binding proteins and a cholesterolgenic enzyme. J. Dairy Sci. 95:318-327. https://doi.org/10.3168/jds.2011-4465.

Tamaki, H., C. L. Wright, X. Li, Q. Lin, C. Hwang, S. Wang, J. Thimmapuram, Y. Kamagata, and W. T. Liu. 2011. Analysis of 16S rRNA amplicon sequencing options on the Roche/454 next-generation titanium sequencing platform. PLoS One 6:e25263. https:// doi.org/10.1371/journal.pone.0025263.

Weimer, P. J., D. M. Stevenson, H. C. Mantovani, and S. L. C. Man. 2010. Host specificity of the ruminal bacterial community in the dairy cow following near-total exchange of ruminal contents. J. Dairy Sci. 93:5902-5912. https://doi.org/10.3168/jds.2010-3500.

Wetzels, S. U., E. Mann, B. U. Metzler-Zebeli, P. Pourazad, M. Qumar, F. Klevenhusen, Q. Zebeli, and S. Schmitz-Esser. 2016. Epimural indicator phylotypes of transiently-induced subacute ruminal acidosis in dairy cattle. Front. Microbiol. 7:274. https://doi .org/10.3389/fmicb.2016.00274.

Wetzels, S. U., E. Mann, P. Pourazad, M. Qumar, B. Pinior, B. U. Metzler-Zebeli, M. Wagner, S. Schmitz-Esser, and Q. Zebeli. 2017. Epimural bacterial community structure in the rumen of Holstein cows with different responses to a long-term subacute ruminal acidosis diet challenge. J. Dairy Sci. 100:1829-1844. https://doi.org/ $10.3168 /$ jds.2016-11620. 
Wickham, H. 2009. ggplot2: Elegant graphics for data analysis. Springer-Verlag, New York, NY. https://doi.org/10.1007/978-0 -387-98141-3.

Yan, L., B. Zhang, and Z. Shen. 2014. Dietary modulation of the expression of genes involved in short-chain fatty acid absorption in the rumen epithelium is related to short-chain fatty acid concentration and $\mathrm{pH}$ in the rumen of goats. J. Dairy Sci. 97:5668-5675. https://doi.org/10.3168/jds.2013-7807.

Ye, J., G. Coulouris, I. Zaretskaya, I. Cutcutache, S. Rozen, and T. Madden. 2012. Primer-BLAST: A tool to design target-specific primers for polymerase chain reaction. BMC Bioinformatics 13:134. https://doi.org/10.1186/1471-2105-13-134.

Zakrzewski, M., A. Goesmann, S. Jaenicke, S. Jünemann, F. Eikmeyer, R. Szczepanowski, W. A. Al-Soud, S. Sørensen, A. Pühler, and A. Schlüter. 2012. Profiling of the metabolically active community from a production-scale biogas plant by means of high-throughput metatranscriptome sequencing. J. Biotechnol. 158:248-258. https: //doi.org/10.1016/j.jbiotec.2012.01.020.
Zhang, R., W. Zhu, and S. Mao. 2016. High concentrate feeding upregulates the expression of inflammation-related genes in the ruminal epithelium of dairy cattle. J. Anim. Sci. Biotechnol. 7:42. https:// doi.org/10.1186/s40104-016-0100-1.

Zhang, S., R. I. Albornoz, J. R. Aschenbach, D. R. Barreda, and G. B. Penner. 2013a. Short-term feed restriction impairs the absorptive function of the reticulorumen and total tract barrier function in beef cattle. J. Anim. Sci. 91:1685-1695. https://doi.org/10.2527/ jas.2012-5669.

Zhang, S., J. R. Aschenbach, D. R. Barreda, and G. B. Penner. 2013b. Recovery of absorptive function of the reticulorumen and total tract barrier function in beef cattle after short-term feed restriction. J. Anim. Sci. 91:1696-1706. https://doi.org/10.2527/jas.2012 -5774 .

Zhao, C., Y. Wang, Z. Peng, X. Sun, G. Sun, X. Yuan, X. Li, and G. Liu. 2019. Subacute ruminal acidosis suppressed the expression of MCT1 in rumen of cows. J. Cell. Physiol. https://doi.org/10 $.1002 /$ jcp. 27829 . 